\title{
A Newer in Vitro Model for the Study of Development of in Vitro Resistance to Penicillin in a Novel Isolate of Streptococcus tigurinus
}

\author{
Shree Dhotre ${ }^{1}$, Basavraj Nagoba ${ }^{2}$, Milind Davane ${ }^{2}$, Mahesh Dharne ${ }^{3}$, Namdev Suryawanshi ${ }^{4}$ \\ ${ }^{1}$ Department of Microbiology, Ashwini Medical College \& Hospital, Kumbhari, Solapur, Maharashtra, India \\ ${ }^{2}$ Department of Microbiology, Maharashtra Institute of Medical Sciences \& Research, Latur, Maharashtra, India \\ ${ }^{3}$ NCIM Resource Centre, CSIR, National Chemical Laboratory, Pashan, Pune, Maharashtra, India \\ ${ }^{4}$ Department of Microbiology, Govt Medical College, Latur, Maharashtra, India
}

\begin{abstract}
Objectives: Streptococcus tigurinus is a new member of the Streptococcus mitis group. It causes various invasive infections. Its isolation from the oral cavity has been reported recently for the first time in our previous study. An attempt has been made to develop a novel in vitro model for the study of development of resistance to penicillin and to find out its effect on susceptibility pattern of other antimicrobial agents in an isolate of $S$. tigurinus.
\end{abstract}

Materials and Methods: An in vitro model mimicking in vivo conditions was developed to induce resistance in $S$. tigurinus with MIC value of $0.12 \mu \mathrm{g} / \mathrm{ml}$ to penicillin by 10 serial passages by sequential exposure to increasing concentration of penicillin.

Results: The in vitro manipulation of original strain of $S$. tigurinus resulted in an increase in MIC value to $8 \mu \mathrm{g} / \mathrm{ml}$ indicating development of resistance to penicillin and a major increase in MIC value of ampicillin from 0.25 to 16 $\mu \mathrm{g} / \mathrm{ml}$, and increase in MIC values of cefepime $(0.12$ to $0.25 \mu \mathrm{g} / \mathrm{ml})$, erythromycin $(0.12$ to $0.25 \mu \mathrm{g} / \mathrm{ml})$, azithromycin $(0.5$ to $1 \mu \mathrm{g} / \mathrm{ml})$ and clarithromycin $(0.25$ to $0.5 \mu \mathrm{g} / \mathrm{ml})$ indicating development of cross-resistance to these antimicrobial agents.

Conclusion: Results indicate that exposure to increasing concentrations of penicillin can induce the development of resistance to penicillin and cross-resistance to other antimicrobial agents. As in vitro conditions are quite similar to in vivo situation, the results obtained are more appreciable than routine methods using artificial media. $J$ Microbiol Infect Dis 2017; 7(4):194-197

Keywords: Streptococcus tigurinus, in vitro resistance, cross-resistance, penicillin

\section{INTRODUCTION}

Streptococcus tigurinus has recently been described as a new member of the Streptococcus mitis group. It causes various invasive infections like infective endocarditis, spondylodiscitis, bacteremia, meningitis, prosthetic joint infections and thoracic empyema $[1,2]$. S. tigurinus has been found to have close relation with $S$. mitis phenotypically as well as genotypically. Recently, its isolation, for the first time, has been reported from the oral cavity from a case of periodontitis in our previous study [3]. Development of resistance to penicillin and cross-resistance to other antibiotics during therapy has been frequently reported in viridans group streptococci (VGS) [4-7] but in vitro studies are mostly overlooked and rarely reported in VGS. However, in vitro studies on development of resistance are commonly reported in Staphylococcus aureus and Pseudomonas aeruginosa [8-11]. The in vitro development of resistance to penicillin has been reported in other species of VGS in our previous study [12] but the in vitro development of resistance to penicillin in $S$. tigurinus has not been studied and reported so far.

In the present study, an attempt has been made to develop an in vitro model to induce in vitro resistance to penicillin in a newer isolate of $S$. tigurinus, which has not been exposed to

Correspondence: Dr. B. S. Nagoba, Assistant Dean, Maharashtra Institute of Medical Sciences \& Research, Latur-413 531, Maharashtra, India 
antimicrobial agents previously and to study its effect on the susceptibility pattern of $S$. tigurinus to other antimicrobial agents. To the best of our knowledge this is the first report on in vitro development of penicillin resistance in $S$. tigurinus and its effect on the susceptibility pattern of other antimicrobial agents.

\section{METHODS}

A novel isolate of $S$. tigurinus, identity of which was confirmed by performing 16S rRNA gene sequence analysis (GenBank / EMBL / DDBI accession number KJ575557) was subjected to find out MIC values against 15 different antimicrobial agents - penicillin G, ampicillin, cefepime, cefotaxime, ceftriaxone, vancomycin, erythromycin, azithromycin, clarithromycin, tetracycline, levofloxacin, ofloxacin, clindamycin, linezolide and quinupristin/dalfopristin by using automated Vitek 2 (bioMérieux) system in accordance with CLSI standards [13]. The isolate of $S$. tigurinus was manipulated in a newer in vitro model to induce resistance to penicillin. A newer in vitro model consisting a central reservoir containing $S$. tigurinus, a diluent reservoir and a waste reservoir (Figure 1). This model was used to study the development of resistance to penicillin. Increasing concentrations of penicillin were added to the central reservoir containing a complex media mimicking/simulating human in vivo like condition designed for this model (Brain - Heart infusion broth, meat particles of beef heart, proteose peptone and sterile defibrinated human blood) through the diluent reservoir. An equal volume of penicillin and test organism containing medium was removed through the waste reservoir. This model offers a continuous culture system, which mimics human in vivo conditions like blood circulation.

S. tigurinus was inoculated into tryptone soya broth and incubated overnight. After achieving the final bacterial concentration of $1 \times 10^{5} \mathrm{CFU} / \mathrm{ml}$ approximately (turbidity matched with McFarland tube No.1), one $\mathrm{ml}$ of broth culture was inoculated into the central reservoir containing $50 \mathrm{ml}$ of the complex media and incubated at 37 ${ }^{0} \mathrm{C}$ for 72 hours in a continuous culture with inflow of media from the diluents reservoir to the central reservoir, the excess medium from central reservoir to waste reservoir with a steady flow rate. S. tigurinus was serially exposed to increasing concentrations of penicillin (starting from $1 / 2$ of the predetermined MIC of $0.12 \mu \mathrm{g} / \mathrm{ml}$ ). The concentration of the penicillin was increased after every 72 hours, serially in the following order starting from $0.05 \mu \mathrm{g} / \mathrm{ml}, 0.1 \mu \mathrm{g} / \mathrm{ml}, 0.2$ $\mu \mathrm{g} / \mathrm{ml}, 0.4 \mu \mathrm{g} / \mathrm{ml}, 0.8 \mu \mathrm{g} / \mathrm{ml}, 1 \mu \mathrm{g} / \mathrm{ml}, 1.2 \mu \mathrm{g} / \mathrm{ml}$, $1.4 \mu \mathrm{g} / \mathrm{ml}, 1.6 \mu \mathrm{g} / \mathrm{ml}, 1.8 \mu \mathrm{g} / \mathrm{ml}, 2 \mu \mathrm{g} / \mathrm{ml}$. Altogether a serial exposure of increasing concentration of the penicillin was done for 11 times using the in vitro model. MIC values of $S$. tigurinus were re-determined after serial passage by using Vitek 2 system to find out the changes induced by serial exposure to increasing concentrations of penicillin.

\section{RESULTS}

An MIC value of penicillin of original strain of $S$. tigurinus was increased from $0.12 \mu \mathrm{g} / \mathrm{ml}$ to 8 $\mu \mathrm{g} / \mathrm{ml}$. A major increase in MIC value of $S$. tigurinus from 0.25 to $16 \mu \mathrm{g} / \mathrm{ml}$ was observed against ampicillin. The slight increase in MIC values of $S$. tigurinus (twice the MIC of original isolate) was seen with cefepime (from 0.12 to $0.25 \mu \mathrm{g} / \mathrm{ml}$ ), erythromycin (from 0.12 to 0.25 $\mu \mathrm{g} / \mathrm{ml}$ ), azithromycin (from 0.5 to $1 \mu \mathrm{g} / \mathrm{ml}$ ) and clarithromycin (from 0.25 to $0.5 \mu \mathrm{g} / \mathrm{ml}$ ). However, no changes in MIC values were observed with other structurally related and unrelated antimicrobial agents after the exposure of $S$. tigurinus to penicillin (Table 1).

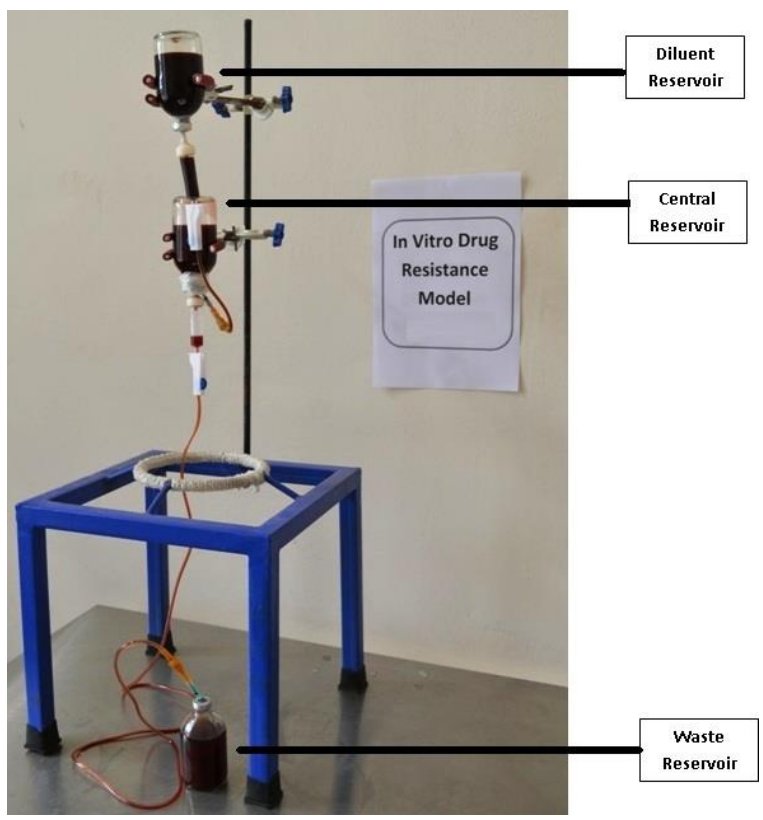

Figure 1. In vitro drug resistance model. 
Table 1. MIC of S. tigurinus before and after exposure to increasing concentration of penicillin in vitro.

\begin{tabular}{lcc}
\hline Antimicrobial agent & $\begin{array}{c}\text { MIC of original strain of } \boldsymbol{S} . \\
\text { tigurinus }(\mu \mathrm{g} / \mathrm{ml})\end{array}$ & $\begin{array}{c}\text { MIC of } \boldsymbol{S} \text {. tigurinus after exposure to increasing concentration } \\
\text { of penicillin }(\boldsymbol{\mu g} / \mathbf{m l})\end{array}$ \\
\hline Penicillin & 0.12 & 8 \\
Ampicillin & 0.25 & 16 \\
Cefepime & 0.12 & 0.25 \\
Cefotaxime & 0.12 & 0.12 \\
Cefitriaxone & 0.12 & 0.12 \\
Vancomycin & 0.5 & 0.5 \\
Erythromycin & 0.12 & 0.25 \\
Azithromycin & 0.5 & 1 \\
Clarithromycin & 0.25 & 0.5 \\
Tetracycline & 0.5 & 0.5 \\
Levofloxacin & 0.5 & 0.5 \\
Ofloxacin & 2 & 2 \\
Clindamycin & 0.25 & 0.25 \\
Quinupristin/Dalfopristin & 2 & 2 \\
Linezolid & 0.25 & 0.25 \\
\hline
\end{tabular}

\section{DISCUSSION}

Repeated exposure of susceptible strains of bacteria to antimicrobial agents is known to make an environment suitable for the development and maintenance of drug resistance in them. The development of resistance to penicillin in VGS during therapy has been reported [4-7], but the reports on in vitro development of resistance to penicillin in VGS are very rare. Although commonly studied and reported in $S$. aureus and $P$. aeruginosa to a variety of antimicrobial agents [8-11], it is very rarely studied and reported in VGS. No previous reports are available on in vitro development of resistance in VGS except for one reported by us [12]. The in vitro development of resistance to penicillin in $S$. tigurinus has not been studied and reported so far. To the best of our knowledge this is the first report on in vitro development of resistance to penicillin in $S$. tigurinus. In the present study, resistance to penicillin was induced in $S$. tigurinus by sequential exposure to increasing concentration of penicillin by using a newer in vitro model, as evidenced by increasing MIC values of $S$. tigurinus after sequential exposure to penicillin. A major change in an MIC value of $S$. tigurinus to penicillin indicates development of resistance to penicillin and a major change in MIC value to ampicillin indicates development of crossresistance to ampicillin following exposure to penicillin (structurally similar antibiotic with similar mode of action). The slight changes in MIC of cefepime, erythromycin, azithromycin and clarithromycin indicate low level of crossresistance to these agents following exposure to penicillin and no major changes in the MIC of rest of the antimicrobial agents indicates no cross-resistance was developed/induced to these agents.

In vitro development of resistance by repeated exposure of susceptible strain of any bacteria using artificial media is very common but always there is variation in in vitro and in vivo susceptibility/resistance pattern because of differences in in vivo and in vitro environmental conditions. To avoid the disparities in the results, an attempt has been made to provide the environmental conditions which are very near to in vivo situation. Although environmental conditions are not exactly similar to in vivo situation, the results of present study are near to reality as they are obtained using a newer in vitro model in which conditions are quite similar to in vivo situation.

The limitations of this study are lack of experimental control group and only one isolate in a study group. It would have been more interesting to study the more number of isolates to obtain more useful and concrete conclusions but unfortunately we could not study more number of strains because of its rarity (In spite of processing 200 specimens we could get only one isolate of $S$. tigurinus).

These results indicate that exposure of susceptible strain of $S$. tigurinus to sublethal concentrations of penicillin not only results into 
development of resistance to penicillin but also leads to development of cross-resistance to other antimicrobial agents. These results show that the resistance could also be developed easily in novel isolates of bacteria which are not exposed to antimicrobial agents ever before.

\section{ACKNOWLEDGMENTS}

Conflict of interest: The authors declare no personal or financial conflict of interest.

Funding disclosure: Non to declare

\section{REFERENCES}

1.Zbinden A, Mueller NJ, Tarr PE, et al. Streptococcus tigurinus, a novel member of the Streptococcus mitis group, causes invasive infections. J Clin Microbiol 2012; 50:2969-2973.

2.Zbinden A, Mueller NJ, Tarr PE, Spröer C, Keller PM, Bloemberg GV. Streptococcus tigurinus sp. nov., isolated from blood of patients with endocarditis, meningitis and spondylodiscitis. Int J Syst Evol Microbiol 2012; 62:2941-2945.

3.Dhotre SV, Mehetre GT, Dharne MS, Suryawanshi MS, Nagoba BS. Isolation of Streptococcus tigurinus - a novel member of the Streptococcus mitis group from a case of periodontitis. FEMS Microbiol Lett 2014;357:131 - 135.

4.Doern GV, Ferraro MJ, Brueggemann AB, Ruoff KL. Emergence of high rates of antimicrobial resistance among viridans group streptococci in the United States. Antimicrob Agents Chemother 1996;40:891-894.

5.Farber BF, Eliopoulos GM, Ward JI, Ruoff KL, Syriopoulou V, Moellering RC Jr. Multiple resistant viridans streptococci: susceptibility to beta-lactam antibiotics and comparison of penicillin-binding protein patterns. Antimicrob Agents Chemother 1983; 24:702-705.

6.Pottumarthy S, Morris AJ. Detection of decreased penicillin susceptibility in viridans group streptococci. Pathol 1998; 30:188-191.

7.Jones RN, Wilson WR. Epidemiology, laboratory detection, and therapy of penicillin-resistant streptococcal infections. Diagn Microbiol Infect Dis 1998; 31:453-459.

8.Nagoba BS, Suryawanshi NM, Wadher BJ, Selkar SP. Norfloxacin induced cross-resistance to fluoroquinolones and non-fluoroquinolone groups of antimicrobial agents in Pseudomonas aeruginosa. Bang J Med Sci 2016; 15:533-537.

9.Deshmukh SR, Nagoba BS, Wadher BJ, Tumane P. Norfloxacin induced cross-resistance to fluoroquinolones \& structurally unrelated antimicrobial agents in coagulase negative staphylococci. Ind J Med Res 1997; 106:461-464.

10.Nagoba BS, Deshmukh SR, Wadher BJ, Gude UG, Gomashe AV, Tumane PM. Induction of resistance to ciprofloxacin \& other fluoroquinolones in clinical \& environmental isolates of Pseudomonas aeruginosa. Ind $\mathrm{J}$ Med Microbiol 1998; 16:29-30.

11.Prasad SV, Ballal M, Shivananda PG. Induction of resistance to fluoroquinolones in clinical and environmental isolates of Pseudomonas aeruginosa. Ind J Pathol Microbiol 2007; 50:94-96.

12.Dhotre SV, Nagoba BS, Suryawanshi NM. Induction of in vitro resistance to penicillin in viridians group streptococci and its effect on susceptibility pattern of other antimicrobial agents. JKIMSU 2016;5: 101-106.

13. Clinical and Laboratory Standards Institute. Performance standards for antimicrobial susceptibility testing; Twenty-third informational supplement. CLSI document M100-S23 Wayne PA: Clinical and Laboratory Standards Institute; 2013. 